\title{
Early X-ray Mapping in Electron Probe Microanalysis
}

\author{
P. Duncumb
}

University of Cambridge, and $5^{\mathrm{A}}$ Woollards Lane, Great Shelford, Cambridge, CB2 5LZ, UK

It was late in 1953 that my supervisor in the Cavendish Laboratory, VE Cosslett, suggested that the topic of my research could be to image a surface in terms of its characteristic X-ray emission, thereby revealing the element distribution. This was to be achieved by combining the scanning technique, already demonstrated by Oatley and McMullan [1] for the SEM, with the intense electron probes used by Cosslett and Nixon [2] in the X-ray point projection microscope. Fortunately Castaing [3] had not already described this technique in his own ground-breaking thesis outlining the principles of microprobe analysis - later saying to me that he had wondered about scanning but believed he had enough to do without it.

I was able to demonstrate the first X-ray maps in 1955 [4], using a converted RCA-EMB electron microscope and, after further development, described some of its applications in my own thesis in 1957. An important arrival on the scene during this period was the gas-flow proportional counter [5] - easy to build and allowing much faster counting than was possible with a Geiger counter. Combined with a simple crystal spectrometer, this gave more than adequate energy resolution for useful applications, and one such trial application [6, 7], for the nearby Tube Investments Research Laboratories, led to commercialization of the instrument (and to my employment there for 28 years). During this period we conceived and built a combined TEM and microprobe analyzer (EMMA) for the study of thin samples [8], also later commercialized. This sequence of development, extending over a period of approximately 15 years, is illustrated in Figs. $1-5$.

Many advances have been made in the last half-century, involving the use of the silicon detectoronly dreamed of in the 1950's. These are well summarized in a recent issue of Microscopy and Microanalysis $[9,10,11]$, describing the evolution of compositional imaging, and its extension to 'spectrum imaging', enabling a far more detailed analysis of line combinations to be made after the data is gathered. Beyond this, it is even practicable to analyze an entire volume in $3 \mathrm{D}$, using a focused ion beam to erode the surface layer by layer. Common to all these techniques, however are statistical limitations on image quality from X-ray quantum noise. This effect is demonstrated in the attached images, and even in this era of push-button instruments deserves the attention of the SEM or probe operator to obtain optimum results [12].

\section{References}

1. D. McMullan, Proc. Inst. El. Eng. 100 Part II (1953) 245

2. V. E. Cosslett and W. C. Nixon, J. App. Phys. 24 (1953) 616

3. R. Castaing, Thesis, University of Paris, ONERA Publ. No. 55 (1952)

4. V. E. Cosslett and P. Duncumb, Nature 177 (1956) 1172

5. U. W. Arndt, W. A. Coates and A. R. Crathorn, Proc. Phys. Soc. B 67 (1954) 357

6. D. A. Melford and P. Duncumb, Metallurgia, 57 No. 341 (1958) 159

7. D. A. Melford, X-ray Microscopy and Microanalysis, Elsevier, Amsterdam, (1960), 407

8. P. Duncumb, 'The Electron Microprobe', John Wiley, New York, (1966) 490

9. J. J. Friel and C. E. Lyman, Microsc. Microanal., 12 Issue 01 (2006) 2

10. D. E. Newbury, Microsc. Microanal., 12 Issue 01 (2006) 26

11. P. G. Kotula, M. R. Keenan, J. R, Microsc. Microanal., 12 Issue 01 (2006) 36

12. Many others at the Cavendish and at TI Research contributed to these developments in the friendly and creative atmosphere that existed in both laboratories. 

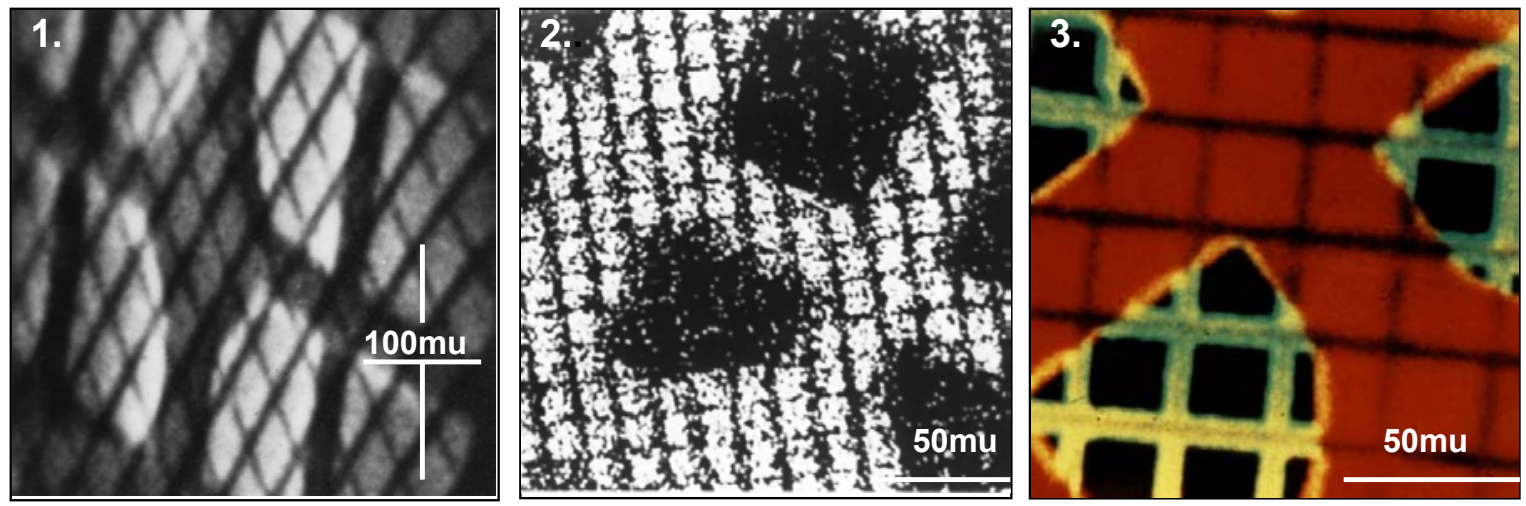

Fig.1. First X-ray map, taken late in 1955, showing $\mathrm{Cu}$ and $\mathrm{Ag}$ grids in absorption contrast distorted, noisy and with no energy discrimination. Would X-ray mapping ever be useful?

Fig.2. $\mathrm{Cu}$ and $\mathrm{Ag}$ grids with direct electron excitation, using a deliberately low probe current to give only 1.5 quanta per pixel. There's hope; it's even noisier but you can still see the grids.

Fig.3. $\mathrm{CuK}$ (red) and AgL lines (green/yellow) separated using a gas proportional counter some discrimination, lots of counts but of no great interest to the practicing metallographer.
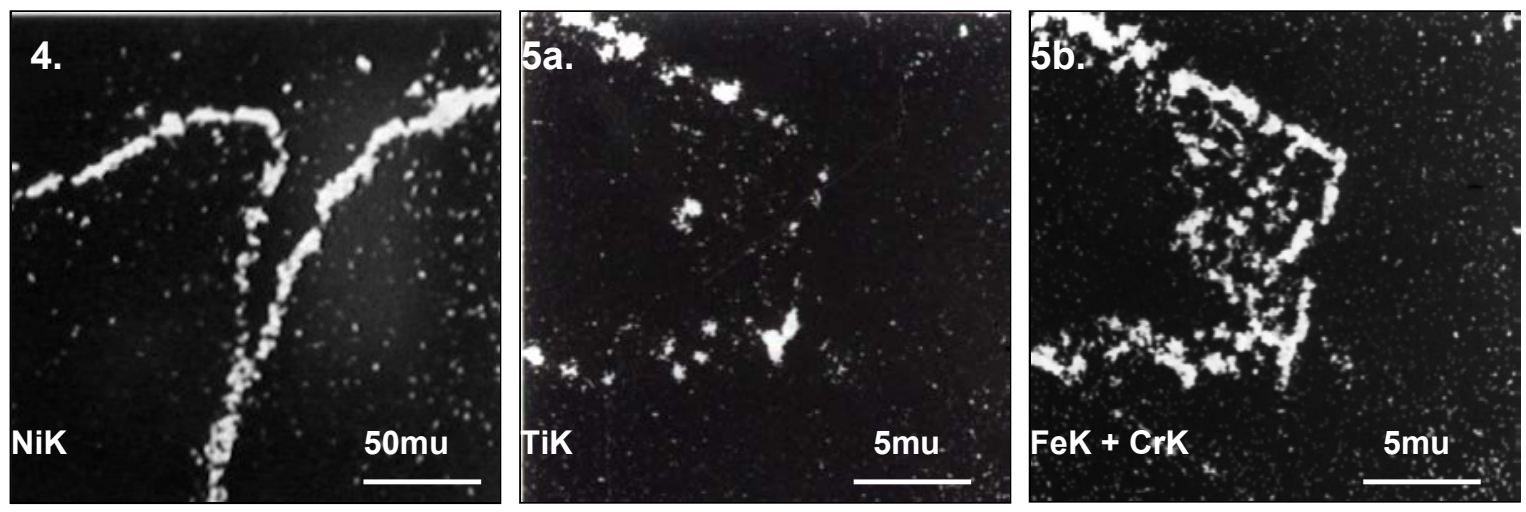

Fig.4. The addition of a crystal spectrometer gave much-needed separation of the Ka lines of the transition elements. This enabled a Ni-rich phase to be identified, lining a deep crack at the surface of a steel billet shown here in transverse section [7]. This enrichment had reduced the melting point below the hot-working temperature so that cohesion between the surface grains was lost. Metallurgists became interested!

Fig.5. Next question:- Could we identify submicron carbides extracted from grain boundaries in a titanium-stabilized stainless steel? Noise again became a problem but intensities were sufficient for X-ray mapping using a proportional counter. Images in EMMA (see text), taken in 1964, resolved particles down to 0.2 micron and separated the Ti well enough (Fig5a) but not the Fe and $\mathrm{Cr}$ (Fig5b). Would the new silicon detectors, just emerging at the time, ever be able to do this? Within a decade the answer was 'Yes'! 